\title{
Transition in place: dynamics, possibilities, and constraints
}

\section{Article}

\section{Accepted Version}

Creative Commons: Attribution-Noncommercial-No Derivative Works 4.0

Nicolosi, E. and Feola, G. (2016) Transition in place:

dynamics, possibilities, and constraints. Geoforum, 76. pp. 153-163. ISSN 0016-7185 doi:

https://doi.org/10.1016/j.geoforum.2016.09.017 Available at https://centaur.reading.ac.uk/67236/

It is advisable to refer to the publisher's version if you intend to cite from the work. See Guidance on citing.

To link to this article DOI: http://dx.doi.org/10.1016/j.geoforum.2016.09.017

Publisher: Elsevier

All outputs in CentAUR are protected by Intellectual Property Rights law, including copyright law. Copyright and IPR is retained by the creators or other copyright holders. Terms and conditions for use of this material are defined in the End User Agreement.

\section{www.reading.ac.uk/centaur}

\section{CentAUR}

Central Archive at the University of Reading

Reading's research outputs online 


\title{
Transition in Place: Dynamics, Possibilities, and Constraints
}

\author{
Emily Nicolosi $^{\mathrm{a}}$ and Giuseppe Feola ${ }^{\mathrm{b}}$ \\ ${ }^{a}$ The University of Utah, Department of Geography, 332 S 1400 E Rm 217, Salt Lake City, UT 84112, \\ USA, Correspondence: emily.nicolosi@gmail.com \\ ${ }^{b}$ Department of Geography and Environmental Science, University of Reading, Whiteknights - PO \\ Box 227, RG66AB Reading, UK
}

\section{Pre-print version}

\section{Suggested citation:}

Nicolosi, E., \& Feola, G. (2016). Transition in place: Dynamics, possibilities, and constraints. Geoforum, 76, 153-163. DOI: 10.1016/j.geoforum.2016.09.017 


\begin{abstract}
The Transition Movement is a translocal phenomenon circulated through transnational grassroots networks. This study explores the geographies of the Transition Movement with a theoretical framework that perceives it as both a social movement and a grassroots innovation. Participant-observation of Transition Salt Lake (TSL), located in the suburban metropolis of Salt Lake City, Utah, was conducted, as the United States remains a largely understudied country in regards to this particular movement. In this pursuit, we asked: (i) how and what this transition initiative draws from geographically extensive and intensive relations, (ii) how it combines place-specific elements and generalized models (embeddedness), and (iii) how this impacts the success of the transition initiative and how these impacts (positive or negative) are generated. Place, space, and scale played a large role in defining the nature, dynamics, possibilities, and constraints of this transition initiative. Specifically, geographically intensive and extensive relations were critical for the mobilization of complementary resources. The Transition model was found to be flexible, allowing for the initiative to adopt those elements that worked in place and to focus on locally relevant topics. TSL faced many challenges identified by previous researchers regarding finances, participation, diversity, and intragroup competition. While networking with other similar groups, TSL demonstrated that fertile environments of activism are incubatory pools for grassroots innovations and social movements, and a trade-off was found with competition between local groups for resources.
\end{abstract}

Keywords: Transition movement; grassroots innovations; social movements; spatial organizational forms; place 


\section{Introduction}

Geographical scholarship has made important contributions to understanding social movements. Geographers have used notions of place, space, and scale to shed light not only on the emergence, diffusion, and scaling-up of social movements, but also on how social movements employ place, space, and scale to pursue their agendas of resistance to neoliberalism and uneven development (Nicholls, 2007, for an overview). Byron Miller's Geography and Social Movements (2000) was the first attempt to link geography with the core literature on social movements; it investigated how differences in state and economic power in and across different locations impact the claims and resource mobilization capacities of social movements. Other inquiries focusing on place have investigated how place-based context influences where social movements occur, their identities, and their potentialities (Routledge, 2003). On the other hand, geographic research concentrating on space has, for example, examined how the spatial unevenness in capitalist development creates differences in political opportunities and available resources (Barnes, 2004), while social movement scholars with an eye to scale have focused on the scalar strategies that some social movements use, for example, by leveraging international attention to put pressure on local institutions (Tarrow and McAdam, 2005).

While earlier studies focused mainly on environmental protests and resistance to neoliberal globalization (Pile and Keith, 1997; Miller, 2000; Featherstone 2003, 2008; Routledge, 2003), scholars have focused more recently on movements that prioritize the construction of socially just and environmentally sustainable alternatives over oppositional stances and social innovation over political strategies (e.g., Pickerill and Maxey, 2009; Brown et al., 2012). The rapid emergence of this particular type of social movement includes, for example, the Transition Movement, permaculture, and eco-housing and ecovillages movements. These movements, which often take the form of intentional communities, tend to 
not be oppositional (Feola, 2014) and to deliberately not engage with politics, i.e. to be postpolitical, as some scholars have discussed (Neal 2013; Kenis and Mathijs, 2014). They place their strategic and practical efforts on building economic and social alternatives, rather than on protests and opposition to dominant systems and structures, although they often perform non-subordination practices (Carlsson and Manning, 2010).

To be sure, the construction of alternatives can be interpreted as a form of resistance and may imply, and possibly even require, forms of deconstruction of dominant imaginaries, institutions, and infrastructures (e.g. Leff, 2010; Carlsson and Manning, 2010). However, a fundamental characteristic of these movements that distinguishes them from other social movements is their performance of societal change 'here and now' through the everyday experimentation of other worlds (Hopkins, 2013), real utopias (Wright, 2013), ecocultures (Böhm et al., 2015), nowtopias (Carlsson, 2008), or concrete utopias (Muraca, 2015). Concrete utopias often challenge the status quo and promote new practices (Pickerill, 2015), institutions, forms of social and economic organisation (e.g., alternative currencies), and systems of provision (e.g., alternative food systems and community energy). In other words, they experiment with different forms of development and often prefigure alternatives to development and to forms of growth-oriented economies and societies.

Concrete utopias render commonly used theories of geographies of social movements insufficient. The inherent nature of concrete utopias as generators of social and often technical innovation calls for alternative theoretical tools in order to fully grasp the dynamics of these social movements and their geographies. In this respect, without overlooking or downplaying critical approaches, some authors have proposed drawing from socio-technical transition studies (Caprotti and Bailey, 2014; Schulz and Bailey, 2014). In the same theoretical vein, others have proposed the notion of using grassroots innovations for sustainability (Seyfang and Smith, 2007; Smith and Seyfang, 2013). Grassroots innovations 
for sustainability emerge as 'networks of activists and organisations generating novel bottom up solutions for sustainable development' (Seyfang and Smith, 2007, p. 585; Smith and Seyfang, 2013). They distinguish themselves from mainstream green business by operating from the bottom-up in civil society arenas, experimenting with often radical social and technological innovations that reflect alternative worldviews and systems of values (Seyfang and Smith, 2007; Seyfang et al., 2010). Grassroots innovations for sustainability are often seen as social experiments and incubators of options that prefigure possible just and sustainable futures (Haxeltine and Seyfang, 2009).

As argued by Seyfang et al. (2010) and Hargreaves et al. (2013) and shown in subsequent studies (e.g., Seyfang and Longhurst, 2016), grassroots innovations and transition studies can complement social movement theories in very insightful ways. However, few authors have connected these strands specifically in geographical literature (e.g., Schulz and Bailey, 2014; Longhurst, 2015; Feola and Butt, 2015), and the potential for theoretical hybridization remains largely untapped. In contrast, more traditional perspectives on the geographies of social movements, including political ecology, rational theory, and poststructuralism, seem to have been pursued more widely (e.g., Beaumont and Nicholls, 2007; Nicholls, 2007).

Beside the innovative potential of concrete utopias, their often translocal character further challenges current geographical theories. Since the early 2000s, social movements have become increasingly translocal (Della Porta and Diani, 2006), largely as a result of the spread of information technologies, social media, and the increasing movement of people in a globalized world, which has facilitated the transfer of repertoires and activism models across national boundaries. Examples of such translocal networks are the Transition Network and the Global Ecovillage Network, both of which connect local initiatives that use the same repertoires across multiple countries. The international hubs of these networks produce and 
circulate a common narrative and sets of practical action models through handbooks, guidelines, training courses, and learning materials that are widely disseminated online. These handbooks and materials formalize successful local experiences and constitute models of practices that local groups elsewhere use to inspire and inform social action. These models are translocal rather than transnational; that is, they occur in place but are circulated through transnational grassroots networks and rooted simultaneously in distinct local cultural contexts.

In the past, geographers have investigated cross-boundary and global movements, but they have mostly focused on transnational networks of different movements bonded by common grievances and agendas, such as anti-globalisation movements (e.g., Routledge, 2003; Featherstone, 2003). New and largely neglected geographical questions can therefore be posed, for instance, around the cultural embeddedness of models of activism; the link between translocal practices, networks, and flows of material and immaterial resources; and the potential for and implications of scaling-up as a strategic goal of movements that have developed through the replication of local practices.

In this paper, we explore these questions through a case study of the Transition Movement in Salt Lake City, Utah (United States of America). The paper sets out to investigate the geographies of Transition Salt Lake and, more specifically, (i) how and what this transition initiative draws from geographically extensive and intensive relations, (ii) how it combines place-specific elements and generalized models (embeddedness), and (iii) what impacts this has on the success of the transition initiative and how these impacts (positive or negative) are generated. 


\section{The Transition Movement}

The Transition Towns idea was born out of a permaculture class that founder Rob Hopkins taught in Kinsdale, Ireland in 2005. His students' project was to apply permaculture principles to overcoming the problem of peak oil, the point after which the rate of oil production will decline due to diminishing oil resources. The class culminated in an 'Energy Descent Action Plan' for towns that envisioned a post-carbon future, with a stage-based plan of implementation. Hopkins subsequently moved to Totnes, England, where he co-founded the Transition Movement and started the first Transition Town, Transition Town Totnes. Subsequently, Transition Towns were formed in other UK villages and later in localities around the globe. In 2007, the Transition Network was established as the operational structure of the Transition Movement to support activities and develop and disseminate information to all Transition Towns.

\subsection{Globally located grievances}

The primary grievances of the Transition Movement have traditionally been climate change and peak oil, which were identified as the 'two toughest challenges facing humankind at the start of this 21st century' (Brangwyn and Hopkins, 2008, p. 3) and are linked to the common root problem of the societal addiction to oil (Hopkins, 2008). More recently, the financial and economic crisis has gained prominence among the concerns of the Transition Movement (Hopkins, 2011).

The Transition Movement aims to build resilient communities, where resilience means the capability to respond to external stresses, i.e., to keep functioning and thriving without cheap oil and in the face of climate change (Hopkins, 2011). Thus, while peak oil, climate change, and the economic crisis are challenges, they are also seen as opportunities for positive change in the local community (Hopkins, 2008). Change (transition) is to be 
achieved primarily through social rather than technological means. While the Transition Movement also promotes environmentally friendly technologies, it is wary of embracing technology as a panacea, as it is not able to address the root causes of peak oil and climate change. Instead, technology promotes participation in the community, social learning, and social innovation through the creativity, motivation, and knowledge that local communities have the potential to unleash (Hopkins, 2011).

The Transition Movement identifies as apolitical and does not aim to take political power, nor does it engage in traditional forms of political protests (e.g., rallies or civil disobedience). Yet its focus on relocalisation as a solution to intertwined problems of climate change, peak oil, and globalisation can be seen as a form of political action (North, 2010). Relocalisation involves the diversification of local economies and the reduction of the dependency on unstable global markets and increasingly expensive transport. With regards to collective action, the emphasis on relocalisation signals the willingness to take direct action and to foster innovation capacity without waiting for national or local political institutions or the business sector to intervene. Transition Towns usually address, in a diverse and placespecific manner, a rather definite set of themes, among which food, transport, energy, and local currencies are the most frequent (Feola and Nunes, 2014).

\subsection{Transition model}

The Transition Movement has developed a set of guidelines over time, including a Transition Handbook (Hopkins, 2008), a Transition Initiatives Primer (Brangwyn and Hopkins, 2008), and a Transition Companion (Hopkins, 2011). Originally, transition was thought of as evolving through the implementation of 12 steps, outlined in The Transition Handbook (Hopkins, 2008). The 12 steps were created 'not to impose a system, but because people seemed to find them useful' (Hopkins, 2011, p. 78). After the experience of the 
residents of Transition Town Totnes, who completed all 12 steps but whose work was not yet done, the label 'steps' was withdrawn in favor of 'ingredients' (Hopkins, 2011, pp. 78-79). The guide following The Transition Handbook, The Transition Companion, revised the steps into 'Ingredients of Transition' and 'Tools of Transition' (Hopkins, 2008, 2011). From then on, transition has been thought of as resulting from action toward a series of areas, namely (1) starting out, (2) deepening, (3) connecting, (4) building, and (5) daring to dream (Hopkins, 2011). A set of Transition 'ingredients' is associated with each area, in which the ingredients were elaborated by generalizing the experience of successful Transition Towns globally. Communities can adapt these steps to their place-specific situation. Therefore, the ingredients do not need to make up a compulsory list, nor must they be followed in a particular order. However, the 12 steps and ingredients set a clear path of action that communities should follow to develop thriving local transition initiatives.

\subsection{Transition Network}

The mode of diffusion for the Transition model is the Transition Network (www.transitionnetwork.org), which is made up of local transition initiatives and national hubs. The central point of reference is the Transition Town Totnes, which functions as the international hub. The Transition Network develops the grand narrative and respective documentation. It produces the above-mentioned guidelines in addition to delivering training for members of Transition Towns, providing consultancy services, and facilitating information exchange and learning among local initiatives (Feola, 2014). The documentation and informational materials can be accessed through both the Internet and print resources.

Importantly, the network also established a system of accreditation, a set of criteria that communities that desire to be recognised as 'official' members of the network must comply with, such as having attended a training session, having drafted and approved a 
constitution, being composed of at least four to five people, and demonstrating a commitment to networking with others, including local and national authorities. Local transition initiatives that are inspired by the Transition Movement principles but that do not comply with these criteria are listed as 'Muller'. As of April 2016, there were 20 accredited national hubs and 1,258 initiatives, 472 of which had official status, while 779 were 'Mullers' (Transition Network, n.d.).

\section{Academic context}

While it is outside the scope of this article to conduct an exhaustive review of the vast literature on the geographies of social movements and grassroots innovations for sustainability, this section summarizes three current and interrelated academic debates that have informed this study.

\subsection{Geographically intensive and extensive relations}

Geographical inquiries into social movements regarding place, space, and scale have not come without criticism. These three concepts hinge upon a geographical conceptualisation of territoriality: that territories are bounded, definable spaces nested within one another and made distinct by different political, economic, social, and cultural institutions that produce distinct identities (Beaumont and Nicholls, 2007). Massey (2004) argued that this emphasis on territoriality, specifically within constructions of place and scale, assumes that people within a certain place are homogenous, which is at odds with the reality of the internal plurality of any given place. Similarly, Amin (2004) contended that a territorial conceptualisation of place and scale is groundless, as boundaries are no longer necessarily tied to place within the context of globalisation. Finding flaws in the dominant, binary conceptualisation of the local versus the global, Amin (2004) insisted that globalisation 
renders space aterritorial and ascalar due to the nearly unrestricted flows of people, ideas, and materials across space. Featherstone $(2003 ; 2005)$ also critiqued the binary construction of the global and the local, arguing that what produces interpersonal differences does not necessarily have to do with place and is not bounded by place. On the contrary, Featherstone (2003) insisted that interests and identities come about through the interaction of people in different places. These perspectives represent a 'relational', as opposed to a 'territorial', approach, a theoretical position founded on the idea that place is unbounded by territory and that the global and the local are infused with one another via the mass interconnections between places and spaces in a globalised world.

Finding a space between relationality and territoriality, Nicholls (2007) and Beaumont and Nicholls (2007) put forth a more nuanced argument that an utterly relational perspective, where all notions of territory dissolve, precludes the reality of particular instances wherein territory does contribute to the character of a place. Nicholls' (2007) and Beaumont and Nicholls' (2007) conceptualisations incorporate the notion that in some cases, a relational perspective is undeniable in that flows cannot be located in space, but in others, scale and place are territorially bound. A territorial definition becomes irrefutable, for example, in looking at national boundaries, which remain distinctly territorial and contain differences in political power (Nicholls, 2007).

In relation to social movements, the stability provided by a particular territory can increase the chances for face-to-face encounters between activists, which may in turn facilitate the growth of social movements. Nicholls (2007) refers to this as 'territorially intensive relations', insisting that these relations facilitated by geographical stability and proximity are essential in procuring high-grade resources. The high-grade resources to which Nicholls (2007) refers are strong-tie relations that allow activists to build trust, exchange tacit knowledge, and socialise and connect with each other through a particular set of values. This 
creates a culture of committed activism, which is essential for engaging in the risky activities for which social movements call.

On the other end of the spectrum, Nicholls argues that 'geographically extensive relations', wherein ties between actors are weak and stretch across larger geographical spaces, aid in obtaining generic, low-grade resources (e.g., 'money, codified information, political support') (Nicholls, 2007, p. 619). Both geographically extensive and intensive relations are essential because they provide different types of necessary resources for social movements. The geographical level of territorialisation, or 'institutionalisation of network connections in specific places', as Beaumont and Nicholls (2007, p. 2559) define it, depends on the place-bound political context.

Various authors have argued that the Transition Movement is in essence a localisation (or 'relocalisation') movement (North, 2010; North and Longhurst, 2013; Kenis and Mathijis, 2014; Alloun and Alexander, 2014). Localisation, though, does not imply isolation or disconnection from global networks (North, 2010). In fact, as Feola and Nunes (2014) argued, successful Transition Towns engage in a combination of inter-scalar (geographically extensive) and local (geographically intensive) learning processes facilitated by the Transition Network. Local transition initiatives remain determined by situated processes but benefit from geographically extensive relations in the form of the interaction with and support of other initiatives and the ability of national and transnational network hubs to generalise and socialise organisational principles. For example, the Transition Network seems capable of elaborating on generic transition principles derived from 'unique' local experiences that overall seem to be effective in other unique local contexts. The diffusion of these principles in the network, together with common narratives and the provision of training by the international and some national hubs (transition training), informs collective local action and the socialisation of the movement's values (Feola and Nunes 2014). Furthermore, Feola and 
Nunes (2014) have shown that Transition Towns often cooperate with other Transition Towns in the network. More importantly, Transition Towns located in areas characterised by a higher density of other Transition Towns, and where there are active regional or national Transition Network hubs, have a greater chance of interacting with other Transition Towns, which seems to positively influence the likelihood of a Transition Town's prosperity. This seems to confirm the positive role played by networking among grassroots innovations for their success (Seyfang and Longhurst, 2013), and it suggests the importance of 'offline' contact despite the growing use of online tools for communication, information sharing, and recruitment. It is also evidence of the importance of geographically extensive relations for obtaining low-grade resources, especially information in this case.

\subsection{Diffusion}

It is widely acknowledged that processes of social movement diffusion are often spatially structured, although authors agree to a lesser extent about the sources of diffusion's spatial unevenness. For example, Hedström (1994) showed that trade unions in Sweden diffused through social networks and that these were shaped by the actors' (i.e., nodes') spatial locations. However, Andrews and Biggs (2006) found that the spatial structure of protest movements in the USA in the 1960s was determined by the uneven distribution of some contextual factors, such as a large student population and more favourable political opportunities, rather than the spatial location of actors in relevant social networks.

Some authors have specifically investigated social movement diffusion across countries. Among them, Tarrow (2005) identified three diffusion pathways, namely relational (i.e., via interpersonal contact and communication), non-relational (i.e., via the media), and mediated (i.e., via movement brokers) diffusion. Strang and Soule (1998) focused on the role of spatial proximity as an enabler of interaction and influence that leads to social movement 
diffusion, but they argued that other mechanisms may be at play, including social media, change agents, strong and weak social ties (related to cohesion and information, respectively), and prestige. As Boschma (2005) also suggests, spatial or geographical proximity may not be a necessary or sufficient condition for social movement diffusion within or across national borders. In fact, Soule (2004) highlighted the importance of cultural proximity, or 'framing', as the process through which the movement's identity is shaped via the social construction and attribution of similarity when social networks and social ties are absent. Transnational movements create collective identities through 'framing' in both relational (i.e., through personal contact) and non-relational (i.e., through channels of information diffusion and online media) forms of connection.

With the spread of the internet and social media, the interplay of geographical and cultural proximity has attracted the attention of students of social movements. Research in this area suggests that the growing use of new media does not result in a less spatially structured spread but rather in reinforced or new spatial structures of social movement diffusion. While in principle the internet facilitates less spatially dependent ties and therefore may influence diffusion towards less spatially structured patterns, factors such as the digital divide among countries and age cohorts, the difficulty of translating virtual connection into practical collective action, and the tendency of virtual networks to form, materialise, and claim their agendas in particular places result in spatially structured social movement diffusion (Diani, 2000; Norris, 2001; Lim, 2014).

Studies of the diffusion of the Transition Movement across Europe have shown that its diffusion, like that of many other social movements, is spatially uneven; that is, Transition Towns are more likely to emerge in some places than in others (Feola and Butt, 2015; Feola and Him, 2016). Scholars have also shed light on the specific conditions for and the mechanism of diffusion of the Transition Movement. The evidence collected suggests that the 
diffusion of the Transition Movement is facilitated by pre-existing place-based and unevenly distributed conditions. In studies in Great Britain and Italy, these conditions included progressive political colour and progressive place identity, tight local social networks, preexisting civic society networks, and a culture of collaboration (Bailey et al., 2010; Feola and Butt, 2015). Regarding the mechanisms of diffusion, Shawki (2013) showed that the Transition Movement has diffused through a combination of the three diffusion pathways identified by Tarrow (2005), whereby non-relational diffusion makes activists initially aware of initiatives in other countries and relational diffusion makes possible the in-depth exchange of ideas, information, and experiences. The Transition Movement has also benefitted from movement brokers and translators in mediated diffusion (Shawki, 2013), where translators can be individuals or organisations that connect local and global activist communities. In the Transition Network, such translation is often done by national and international network hubs through the internet, social events like the International Transition Conference, and training (Feola and Nunes, 2014; Feola and Butt, 2015).

\subsection{Success and failure}

Research on community action and grassroots innovations for sustainability has offered many positive accounts of particular low-carbon local experiments, but more critical views have also emerged (Walker, 2011; Heiskanen et al., 2015). In particular, while the role of 'community' is central to grassroots innovations (Aiken, 2012), it has been shown that grassroots innovations do not always operate internally as smoothly as idealised or function as inclusive and supportive communities of practice (Mulugetta et al., 2010; Walker, 2011). Furthermore, grassroots innovations, like many civic society organisations relying on volunteers, often struggle with securing and sustaining participation over time (Seyfang and Smith, 2007; Hoffman and High-Pippert, 2010; Middlemiss and Parrish, 2010), which limits 
their ability to promote innovation in the community (Kirwan et al., 2013; Ornetzelder and Rohracher, 2013). The scarcity or complete lack of secure inflow streams of financial resources often hinders grassroots action (e.g., Middlemiss and Parrish, 2010; Seyfang and Longhurst, 2013). Finally, grassroots innovations do not always mirror the diversity (e.g., ethnic) of local communities, and consequently struggle to establish strong links with the larger community (Seyfang and Smith, 2007). On the other hand, networking with other local or global actors, including other grassroots innovations, has been shown to be critical for success (Seyfang and Longhurst, 2013).

The evidence on the success and failure of grassroots innovations for sustainability is mostly based on in-depth studies of individual experiments, while only a few studies have attempted to identify more general patterns (Feola and Nunes, 2014). Following Feola and Nunes (2014), the conditions for successful grassroots innovations can be usefully divided in the following five groups: transition initiative characteristics (for Transition Towns), membership, resources, organisation, and context (Table 1). 
Table 1. Factors of success of grassroots innovations for sustainability. Adapted from Feola and Nunes (2014).

\begin{tabular}{|c|c|c|}
\hline Group of factors & Factor & Sample reference \\
\hline \multirow{6}{*}{$\begin{array}{l}\text { Transition } \\
\text { initiative } \\
\text { characteristics }\end{array}$} & Rurality & Smith (2011) \\
\hline & Legal status & Mulgan (2006) \\
\hline & Activities/themes addressed & - \\
\hline & $\begin{array}{l}\text { Years needed for a TI to become } \\
\text { official }\end{array}$ & - \\
\hline & Official vs. mulling & Brangwyn and Hopkins (2008) \\
\hline & Country & - \\
\hline \multirow[t]{5}{*}{ Members } & Age & Middlemiss and Parrish (2010) \\
\hline & Skills & $\begin{array}{l}\text { Hoffman and High-Pippert } \\
\text { (2010) }\end{array}$ \\
\hline & Representation of minorities/diversity & Smith (2011); Quilley (2012) \\
\hline & Large number of founders & Middlemiss and Parrish (2010) \\
\hline & Educational level & Middlemiss and Parrish (2010) \\
\hline \multirow[t]{8}{*}{ Organisation } & Recruitment & $\begin{array}{l}\text { Hoffman and High-Pippert } \\
\text { (2010) }\end{array}$ \\
\hline & Paid staff & Wells (2011) \\
\hline & Internal conflict/ideology & Seyfang and Smith (2007) \\
\hline & Steering group & Hopkins (2011) \\
\hline & Size of steering group & Brangwyn and Hopkins (2008) \\
\hline & Internal communication & $\begin{array}{l}\text { Ornetzelder and Rohracher } \\
\text { (2013) }\end{array}$ \\
\hline & External communication & Hopkins (2011) \\
\hline & Internal organization by subgroups & Brangwyn and Hopkins (2008) \\
\hline \multirow[t]{4}{*}{ Resources } & Infrastructure & $\begin{array}{l}\text { Hoffman and High-Pippert } \\
(2010)\end{array}$ \\
\hline & Funding & Middlemiss and Parrish (2010) \\
\hline & Time resources & Middlemiss and Parrish (2010) \\
\hline & $\begin{array}{l}\text { Complementary high-grade and low- } \\
\text { grade resources through a } \\
\text { combination of geographically } \\
\text { extensive and intensive relations }\end{array}$ & Beaumont \& Nicholls (2007) \\
\hline \multirow[t]{4}{*}{ Context } & Pre-existence of bottom-up initiatives & $\begin{array}{l}\text { Ornetzelder and Rohracher } \\
\text { (2013) }\end{array}$ \\
\hline & $\begin{array}{l}\text { Pre-existence of participatory } \\
\text { democracy }\end{array}$ & Wells (2011) \\
\hline & $\begin{array}{l}\text { Cooperation/partnership with other } \\
\text { organisations }\end{array}$ & $\begin{array}{l}\text { Ornetzelder and Rohracher } \\
(2013)\end{array}$ \\
\hline & Favourable context & Mulgan (2006) \\
\hline
\end{tabular}


Studies that have specifically examined the development of the Transition Network have substantially confirmed the above table (Smith, 2011; Wells, 2011; Feola and Nunes, 2014). Furthermore, it has been shown that ideological disputes, e.g., between political and apolitical and between confrontational and collaborative strands, may also act as a source of internal conflict and a barrier to the successful development of Transition Towns (Smith, 2011; Biddau et al., 2016). Finally, from a geographical perspective, it was shown that the Transition Network enables inter-scalar connections and learning processes (section 3.1), while at the local level, Feola and Nunes (2014) suggested that direct interaction between local transition initiatives, which is facilitated by their geographical proximity, is an important factor of success. Whether Transition Towns are more likely to thrive in rural or urban contexts is up for debate. North and Longhurst (2013) suggested that urban, as opposed to rural, places may offer more conducive conditions for local transition initiatives, whereas Feola and Nunes (2014) found that Transition Towns in rural settings are more likely to be successful, possibly because of a stronger place attachment and better representation of social difference.

\section{Methodology}

To study the geographies of the Transition Movement, ethnographic research was conducted using the case study of Transition Salt Lake (TSL). This Transition Town is located in the suburban metropolis of Salt Lake City (SLC), Utah. This provides unique insight into the Transition Movement, as research on this movement has largely focused on Europe. Using the method of participant-observation, from April 2014 through June 2016, one of the authors was an active member and conscious observer in TSL (Hammersley \& Atkinson, 1995). TSL activities typically included biweekly Steering Group meetings, monthly potlucks and work parties, and occasional 'reskilling' events. In addition, the 
participant-observation research included more informal encounters with members, like volunteering in members' gardens and at events hosted by other individuals and organisations that TSL members attended, including film screenings, book clubs, and protests. In all of the aforementioned circumstances, field notes were taken and quotes were recorded as accurately as possible. This observational material was supplemented with document analysis of books, websites, and video material produced and consumed by TSL (e.g., The Transition Handbook and the group's Facebook page), in addition to the Steering Group's meeting minutes since its beginnings in 2012. The names of participants in TSL and other local groups have been generalized here to protect their privacy.

\subsection{The case study: Transition Salt Lake}

Transition Salt Lake's formation and first years were very much guided by the Transition model (Hopkins, 2008, 2011). TSL emerged in 2011 with a book club on The Transition Handbook hosted at the First Unitarian Church of SLC, a Unitarian Universalist Church, which is a non-denominational organization devoted to social justice (First Unitarian Church, n.d.). This reading group decided to start a local Transition Town by forming a Steering Group. While no one in TSL had ever attended an official Transition training, the group applied for and gained official status from the Transition Network in August 2012. As of June 2016, TSL had about 125 members, with a six-member Steering Group.

The members of the Steering Group are a group of passionate individuals who are white, well educated, and mostly retired. The members of the Steering Group were largely connected before the establishment of TSL through common membership in the Unitarian Universalist Church of SLC and also through common membership in several different environmentalist groups and networks. The members of TSL were primarily recruited through Garden Group potlucks and tabling at events in SLC. The demographic makeup of 
the larger TSL membership also tends to be white, well educated, and older in age.

\section{Results and Discussion}

\subsection{Geographically extensive and intensive relations}

The diffusion of low-grade resources (generic information) from the Transition Network out to this individual initiative is evident in TSL, as is the critical nature of these low-grade resources for the development of the group. The primary conduit for this diffusion is the Steering Group, an entity that TSL decided to form based on the suggestion of The Transition Handbook, which has always been their primary guide for transition (Hopkins, 2008).

TSL's Steering Group consists of six members who meet on a bi-weekly basis to organize the activities and events of the larger group. Their meetings are usually centred around discussions of Transition themes garnered from official Transition documents and other non-Transition documents that provide additional information around these Transition themes, as well as how they will be implemented with group activities and events. In this way, the Steering Group processes the information coming from the Transition Network. When they then meet with the larger group and the general public, this knowledge is shared through conversation, formal instruction, and experiential learning. The larger membership of TSL is less committed in terms of time and effort, so the Steering Group is critical in linking the local group with the larger, global network.

The low-grade resources the Transition Network contributes are complemented by the high-grade resources TSL mobilises on the ground. Within SLC, urban territorialisation is evident in thick networks of ties between actors, ties whose intensity is based on the differing frequencies of interaction between the Steering Group and the general membership.

The members of the Steering Group have the strongest ties within TSL, as they spend 
the most time together, not only in meetings but also within common memberships in other organizations (e.g., The First Unitarian Church, Citizen's Climate Lobby), and through informal 'hanging out' (e.g., having dinner together, helping each other in their gardens). Regular face-to-face interaction facilitated by the spatial proximity (living close by) of these actors contributes to the strong ties formed between them, in turn facilitating the growth of several important resources, including the exchange of tacit knowledge, socialisation to Transition values, and the creation of trust, a sense of belonging, and a common identity. This cultivates interpersonal support, creating a culture of committed activism that is essential to keeping TSL going, avoiding burn-out, facing the loss felt in relation to climate change and alienation from capitalist culture, and celebrating the joy generated through collectively working on innovative grassroots solutions to global problems. As one Steering Group member commented, 'It's so nice to have this group, to be surrounded by people who care and are trying to do something' (personal communication, January 5, 2015). In a practical sense, the strong bonds and values between the Steering Group members and the abundance of time spent together also facilitate the process of organising and planning for TSL activities and events, including the material resources necessary for these activities.

The general membership of TSL does not interact as often as the Steering Group, but they still have strong bonds with each other, relationships that would not exist without the face-to-face interaction allowed for by their spatial proximity (i.e. living in SLC, especially the eastern side). Their interactions occur primarily at monthly potlucks and work parties, and secondarily at other events such as The Clean Air Fair and climate change protests. The potlucks are held once a month and are organized by the Steering Group, but they are hosted by different members each month. Potlucks allow members to gain practical information around growing food and also facilitate access to material resources (e.g., plant/seed exchange). On a social level, potlucks socialise members to the Transition emphasis on local 
food and community and strengthen the TSL social network.

Potlucks are usually followed by work parties, collaborations in which one member of the TSL group solicits the help of the larger group to take on a large-scale permaculture garden project. Work parties help members obtain important practical material and human resources (e.g., organic matter, collective human labor) that help participants move towards localised food production. Through the experiential learning, members also gain practical knowledge of permaculture. In addition, work parties reinforce the Transition narrative within the group. This includes Transition perspectives on the importance of localisation and local food production, which particularly emphasises re-envisioning what a suburban backyard could look like (i.e., that it can be an edible space, reducing dependency on nonlocal food) through the positive, fun environment centred around helping each other achieve greater self-sufficiency.

A key finding here is that the Steering Group acts as a social broker between the TSL general membership and the Transition Network. It is the link between geographically extensive and intensive relational levels. The Steering Group also acts as translators in that they translate the global grievances identified by the Transition Network into localised experiences, especially TSL's own orientation towards social change as a positive experience of 'doing'. This is embodied well in one TSL member's explanation of Transition to a curious member of the general public at a tabling event: 'Transition is about moving from fossil fuel dependence to local resilience, and with joy' (personal communication, August 30, 2014).

What also became evident from this case study is the importance of spatial proximity in creating the types of strong relations that facilitate the process of building and maintaining a social movement on the ground. As stated earlier, the ties between Steering Group members are very strong, which helps the group maintain its large commitment to the movement. For 
the general membership, interpersonal interaction is critical in the exchange of the material and human resources and alternative values necessary for developing and spreading grassroots innovations, as Feola and Nunes (2014) have also found. At the same time, TSL would not exist without its relation to the distant Transition Network, which supports interscalar learning processes and provides critical information and a generalised model for action, again supporting Feola and Nunes' (2014) findings. Furthermore, the findings here provide support for Nicholls' (2007) and Beaumont and Nicholls' (2007) argument that strong relations are facilitated by geographical proximity and result in the procurement of high-grade resources complementary to those low-grade resources obtained via geographically extensive relations. However, these findings do not support Nicholls' (2007) and Beaumont and Nicholls' (2007) argument that the way social movements organise themselves in space is a result of differences in political context. Instead, the way in which the Transition Movement spatially defines its grievances as global and solutions as local is responsible for the geographical level of territorialisation of this movement, which is on the town or city level.

\subsection{Transition model in place}

In addition to the spatial form of relations of the Transition Movement, it is also critical to consider how, from a geographical perspective, the Transition model is adopted in place. Here we consider how place has informed which elements of the Transition model TSL has adopted.

While the Transition Network produces a variety of informational materials, The Transition Handbook was and remains TSL's primary guide (Hopkins, 2008). TSL first began with a reading group of The Transition Handbook, whose participants decided to start a local Transition Town by forming a Steering Group, following step one of the 'Twelve 
Steps to Transition', as outlined in The Transition Handbook (Hopkins, 2008). The development of the group was largely guided by The Transition Handbook, as no member had ever attended an official Transition training. To date, the group has followed nine of the twelve steps and has tended to focus on locally relevant topics in pursing those steps they have chosen, thus exploiting the Transition model's flexibility (Table 2).

Table 2: Twelve Steps of Transition, from Hopkins (2008), adopted and not adopted by TSL.

\begin{tabular}{|c|c|l|l|}
\hline $\begin{array}{c}\text { Step } \\
\#\end{array}$ & $\begin{array}{c}\text { Completed } \\
\text { by TSL }\end{array}$ & \multicolumn{1}{|c|}{ Item } & \multicolumn{1}{c|}{ Notes re: TSL } \\
\hline 1 & X & $\begin{array}{l}\text { Set up a Steering Group and } \\
\text { design its demise from the outset }\end{array}$ & $\begin{array}{l}\text { Set up in 2012, still in } \\
\text { existence as of June 2016 }\end{array}$ \\
\hline 2 & X & Raise awareness & Film screenings, book clubs \\
\hline 3 & X & Lay the foundations & Film screenings, book clubs \\
\hline 4 & X & Organize a Great Unleashing & \\
\hline 5 & X & Form groups & $\begin{array}{l}\text { Garden Group, Heart \& Soul } \\
\text { Group, Gifting Circle }\end{array}$ \\
\hline 6 & & Use Open Space & \\
\hline 7 & $\mathrm{X}$ & $\begin{array}{l}\text { Develop visible practical } \\
\text { manifestations of the project }\end{array}$ & \\
\hline 8 & $\mathrm{X}$ & Facilitate the Great Reskilling & Heavy emphasis, food-focused \\
\hline 9 & & $\begin{array}{l}\text { Build a bridge to local } \\
\text { government }\end{array}$ & \\
\hline 10 & $\mathrm{X}$ & Honor the elders & \\
\hline 11 & $\mathrm{X}$ & Let it go where it wants to go & \\
\hline 12 & & $\begin{array}{l}\text { Create an Energy Descent } \\
\text { Action Plan }\end{array}$ & \\
\hline & & & \\
\hline
\end{tabular}

The overwhelming focus of TSL has been on 'reskillings', demonstrations of and training in utilitarian skills that reduce dependency on the capitalist economy (i.e., grassroots innovations for sustainability), both at public events and at work parties. The majority of these have centered around food growing (Table 3). In general, TSL has followed the Transition model and narrative by adopting its views on peak oil, climate change, and globalisation, as well as the model's solutions to these issues by focusing on grassroots innovations like local food, homemade products, repair as an alternative to consumption, and alternative transportation. In these ways, TSL's social network form and many of its activities were taken from the official Transition model, which significantly aided the group's birth and 
development.

Table 3: Grassroots innovations shared in reskilling workshops by TSL, 2009-2015

\begin{tabular}{|l|l|}
\hline Gardening & $\begin{array}{l}\text { Tool sharpening, compost worm culture, wild edible plant ID and } \\
\text { use, seed starting, seed swaps, swales and berms on } \\
\text { contour/hugelkultur, newspaper pots, a homemade beeswax/honey } \\
\text { separator*, a homemade net frame for dehydrating, hoop-house } \\
\text { construction }\end{array}$ \\
\hline $\begin{array}{l}\text { Food } \\
\text { Preparation/Storage }\end{array}$ & $\begin{array}{l}\text { Solar oven baking and cooking, fermenting sauerkraut, drying } \\
\text { fruits and vegetables, canning, twig (rocket) stove* }\end{array}$ \\
\hline Handmade/Home & $\begin{array}{l}\text { Beeswax candles, laundry soap, bird feeder, hand cream, shampoo, } \\
\text { greeting cards, hand-crank washing machine* }\end{array}$ \\
\hline Repair & Bicycles: fixing flats, darning socks, sewing on buttons \\
\hline Alternative Transit & Electric-assist bicycle, solar car, electric cars* \\
\hline
\end{tabular}

*Discussed by TSL members, but not included in reskilling workshops

TSL has taken a very food-focused direction, following its members' passionate interest in permaculture gardening. It has paid less attention to areas of less interest to group members, though they are outlined in the Transition model, like medicine and health. Its monthly potlucks and work parties are not specifically outlined in any official Transition materials (Hopkins, 2008, 2011). The environmental context of SLC has also played a role in shaping the interests and activities of TSL. For example, TSL has employed permaculture principles attuned to the dry climate in SLC, especially with the group's passion for Hugulkultur, an innovative method of constructing growing beds that employs techniques that help the bed retain water during droughts. TSL members also emphasise the importance of Hugulkultur in light of the impact of climate change in the American southwest. For example, at a Steering Group meeting, a member discussed his efforts to use Hugulkultur in the Holladay Community Garden, 'because we could be going into a 30-year drought' - to which another member responded, 'more like a 30,000 year drought!' (personal communication, June 26, 2015). In these ways, the interests of TSL members and the 
environmental context of SLC have manifested in a unique Transition Town, as it likely could in other places. This is the first manner in which the Transition model shows its flexibility: local initiatives can focus on place-relevant topics but still follow the ingredients.

The political context of SLC has also impacted TSL's adoption of the Transition model. SLC and Utah are predominately Republican, which has made it difficult for the group to follow the step of building bridges with elected officials (Brown, 2014; Hopkins, 2008). While the group has not attempted to reach out to local government, they did express great enthusiasm for a candidate running 'for climate' in the fall 2014 election cycle. In addition, a TSL member ran for State Representative in the fall of 2014, though was unsuccessful. Nonetheless, the group has never had any links with elected government officials. The political context of this place reveals a second way the Transition model is flexible: some ingredients that would be difficult to implement in a particular local context, or that would cause conflict, can be left aside.

Another unique factor of TSL is its relationship with one of the hubs of countercultural activity and political activism in SLC: The First Universalist Church, a Unitarian Universalist church ('UU Church'). Notably, the UU Church is not a Christian organisation but an interdenominational organisation devoted to environmental and social justice that is overtly both politically liberal and active. Activists from a wide range of organisations and causes are members of the UU Church, where formal and informal networking, collaboration, and recruitment occur. The UU Church also supports local groups, including TSL, by providing space for events, meetings, and tabling. Several members of TSL have been recruited through common membership in the UU Church. The UU Church is a very distinct feature of SLC and has significantly shaped TSL in its origins (a book group at the Church), in creating opportunities for networking and recruitment, and in providing a preexisting social network from which TSL can draw. 
In examining how the Transition model is adopted in place, what becomes evident is that the Transition model is flexible. TSL employs this flexibility by choosing the ingredients that work best in the unique place that is SLC, by leaving aside those that do not work, and by focusing on locally relevant topics, like food. This reflects North and Longhurst's (2013) comment that 'the politics of Transition are plastic and generative, offering a range of strategies to the participants' (North and Longhurst, 2013, p. 1434). Indeed, the steps and ingredients towards Transition are a guide rather than a prescription, as Alloun and Alexander (2014) point out. The Transition model is more of a pick-and-choose system, but it is one that provides enough guidance to help groups form and develop. Furthermore, from a theoretical perspective, TSL's focus on reskilling and locally adapted practices like Huglulkutur demonstrates that transition initiatives must be analysed not only as social movements but also as grassroots innovations for sustainability.

\subsection{Success and failure}

The case study of TSL provides some insight into the debate around what factors contribute to the success and failure of grassroots innovations for sustainability and community action. While it is beyond the scope of this research to respond to all strands of this debate, this particular case study does confirm many previous findings in this arena.

First, organizations like TSL that rely on volunteers often struggle to recruit new members and sustain the participation of current members (Seyfang and Smith, 2007; Hoffman and High-Pippert, 2010; Middlemiss and Parrish, 2010). This is certainly the case with TSL, whose general membership has changed greatly over time, with only a few key individuals remaining. It has also been an issue with participation in the Steering Group, which requires a significant commitment in terms of both time and effort. While the Steering Group has remained steady in terms of numbers over time (about six), only two of these 
members have stayed with TSL for the entirety of its existence. Recently, Steering Group members have expressed burnout; they desire to have meetings less frequently and to focus on potlucks and work-parties instead of organizing events and reskillings as well. Part of this is also due to many general TSL and Steering Group members' multiple memberships in other environmental and political organisations, which compete for their time and effort. However, it should also be noted that this may not necessarily translate to a decreased ability to promote innovation in the community, as many of the other projects to which TSL members devote their time are similar to or in line with the goals and activities of the Transition Movement.

In fact, multiple memberships have aided and influenced the group in some ways. TSL members' multiple memberships demonstrate that they think of different social movement organisations as close or at least mutually compatible, which aids in interorganisational cooperation and flows of communication (Diani, 2003). While some scholars have categorised the Transition Movement as apolitical, TSL reveals influences from and connections to political entities and other social movements. For example, several members of TSL are very active in the local chapter of Citizen's Climate Lobby, which advocates for a national carbon tax. These memberships also act as an outlet for TSL members who want to engage in more overt political action. Ties to other local organisations show that the flow of information and ideas does not arrive solely from the Transition Network and official Transition materials but also from a variety of local social movements. Another issue that grassroots innovations commonly face and that TSL has exhibited is a lack of diversity (Seyfang and Smith, 2007). This may in part be due to the demographic spatial split of SLC; the valley is divided into the east side and the west side, with east and west referring to which side of the I-15 highway one lives on. The east side tends to be mostly white, with a higher income and educational attainment than the west side, which is 
predominantly Hispanic and contains several refugee and immigrant communities (Smith, 2013). The members of TSL live on the east side of the valley, which may be to blame in part for their lack of diversity. Steering Group members have expressed a desire to do more outreach on the west side but are constrained by limited resources and by a proclivity to focus on 'doing' rather than organising and administrating. However, other scholars (e.g., Smith, 2011; Quilley, 2012) have suggested that the Transition Movement is not diverse because it is essentially a white, affluent movement. In fact, one of the reasons for the lack of diversity in this case is more practical and is related to organisation and the propensity for executing physical manifestations of Transition.

Diversity may also be thought of in terms of ideology, and in SLC it is impacted by a unique quality: Utah's religious context. The Salt Lake Valley's first white settlers were members of the Church of Jesus Christ of Latter-day Saints (also known as "LDS," or "Mormons") attempting to escape religious persecution (May, 1987). Established as a home for the LDS faith, Salt Lake County remains a predominately Mormon city (51.41 percent LDS), with the state as a whole retaining the largest LDS membership of any other (62.64 percent LDS) (Canham, 2014). The cultural response of non-Mormons to the large presence of Mormons in this area has arguably been the formation of very strong alternative identities. The countercultural scene in SLC is particularly vibrant and active, and it has many expressions and distinct communities (e.g., climate justice activists, local food enthusiasts, the Burning Man community). For TSL, this has resulted in a situation in which they have found it easier to reach out to like-minded individuals within countercultural communities for recruitment, collaboration on events, and the like, though not with the intention of being exclusive. Furthermore, the politically liberal and active identity in this place has evidently produced a fertile environment for social movements, as it has in others (Feola \& Butt, 2015; Feola \& Nunes, 2014; North \& Longhurst, 2013). 
Collaborations with other local groups have also helped TSL cope with a lack of income. As other scholars have pointed out, grassroots activity often suffers from a lack of financial resources (e.g., Middlemiss and Parrish, 2010; Seyfang and Longhurst, 2013). This is certainly the case with TSL, which has never had income. However, this was in part an overt choice made by the Steering Group, who preferred to operate this way as a protest against capitalism. As a result, the group has operated outside of the capitalist economy, but nevertheless has been able to obtain resources through the exchange of home-grown food with, or the outright giving of food to, local businesses, other nonprofits, the UU Church, and individuals in return for their help (e.g., for manure, woodchips, plants, space). In general, there is an attitude among activists that interorganisational goals are mutual. This is exemplified by a member of Revolution United, who commented that, 'we are all in the same struggle, we don't have to wait for change to come down to us, we can make changes ourselves' (personal communication, August 18, 2014). Overall, it is likely that networking with other organisations has been so critical for TSL that they likely would not exist without it, which provides support for other findings about the importance of networking for the transition initiatives (Seyfang and Longhurst, 2016; Feola and Nunes, 2014; Ornetzelder and Rohracher, 2013).

At the same time, the vibrant social movement scene in SLC produces some challenges for TSL. TSL is constantly competing with other groups for members and their engagement and commitment, a critical resource for social movements. Many other organisations in SLC do similar work to TSL, but often with more financial resources, longer histories, professional staff, and a larger presence in the community. This creates competition in terms of both visibility and participation, and TSL has tended to collaborate on events with groups that have different orientations (e.g., social justice). In fact, the founder of TSL had read The Transition Handbook and attempted to organize a Steering Group four or five years 
before TSL started but was unsuccessful not due to the lack of interest, but because everyone he contacted was already so busy with activism in other groups. Looking at TSL in the social movement context of SLC indicates that there seems to be a trade-off between being in a favorable environment and competition with other movements.

Conflict can also arise within the group itself. In the case of Transition, ideological disputes between strands of political versus apolitical thought and confrontation versus collaboration have been identified as a potential problem (Smith, 2011; Biddau et al., 2016). This has arisen to some extent in the case of TSL. Some members have a distaste for political and confrontational action, preferring to embrace a more positive outlook and focus on innovation and the manifestation of alternative practices, while others are more overtly politically active. For the most part, this has not created outright conflict within the group, as the more political members have been able to join other organisations that pursue their preferred modes of activism as well. However, the result of these multiple memberships has been a strain on the time and effort of members, which in some cases has reduced or eliminated participation. Moreover, in practical terms, this indicates not that innovation and traditional political action are incompatible, but that their types of work are distinct and require significant commitments of time and effort.

The internal and external dynamics of transition initiatives all occur under the backdrop of population density and the built environment. The extent to which an urban versus a rural context aids in the success of transition initiatives has been an object of some debate (North \& Longhurst, 2013; Feola and Nunes, 2014). In the case of TSL, the urban context is in some ways beneficial because it gives TSL, which is located in a politically and religiously conservative area, access to more groups and individuals who share similar ideas. This supports the argument of North and Longhurst (2013) that urban centres may be a more powerful locus than the rural context because they allow access to a greater density of 
networks and resources. Nicholls (2007) has also discussed the benefits of the urban context for social movements, as they facilitate the formation of strong relations through spatial proximity and allow for weaker ties among more loosely connected actors who share ideas with the core group. This notion is exemplified by Dave's comments about his attempts to be friendly to his next-door neighbors by giving them lettuce and so on, but was met with unresponsiveness. 'It's better to find community around Salt Lake', he concluded, then admonished his neighbor for tearing out their lawn only to put fresh sod in (personal communication, June 3, 2014). Thus, it is likely that there are trade-offs between rural and urban contexts and that these are also impacted by the unique socio-cultural contexts of different places.

\section{Conclusion}

This study built on and expanded existing knowledge of the geographies of social movements and grassroots innovations. Through the case of the Transition Movement, it has investigated three specific aspects of such geographies: (i) how and what this transition initiative draws from geographically extensive and intensive relations, (ii) how it combines place-specific elements and generalised models (embeddedness), and (iii) what impacts this has on the success of the transition initiative studied and how these impacts (positive or negative) are generated. These questions are at the heart of the phenomenon of translocally networked concrete utopias and shed light on the apparent contradictions of: (i) adopting and deploying generalised action models in locally specific contexts and (ii) being placedependent and path-dependent in relation to local history, culture, and institutions while at the same time being actively internationally networked.

This study shows that looking at the Transition Movement as both a social movement and a grassroots innovation can provide particular insight. Integrating these two theoretical 
perspectives creates a better appreciation of the nature of the Transition phenomenon and consequently allows for a fuller explanation of the interrelationships between local transitions and place and of the ways in which Transition Towns use space and create spaces of action. In relation to scale and flows of information, it permits a more nuanced understanding of the influence Transition Towns may have on change in specific places and in global terms through translocal interconnections.

This paper has shown how place, space, and scale play a role in defining the nature, dynamics, possibilities, and constraints of this transition initiative. The spatial relations of the Transition Movement combine geographically extensive and intensive elements bridged by the brokerage role of the Steering Group. In so doing, it exploits spatial proximity to mobilize high-grade resources and extensive networks to obtain complementary low-grade resources. This study has shown that the Transition model is flexible: initiatives can choose the ingredients that in work well in place, leave aside those that do not, and focus on locally relevant topics, many of which are indeed grassroots innovations adapted to specific places. The case of TSL reflects many of the common factors inhibiting the success of grassroots innovations and social movements, including the difficulty of sustaining participation, the strain caused by lack of financial resources, little diversity, ideological disputes, and competition with other groups. At the same time, networking with other grassroots innovations and social movements has been critical in on-the-ground mobilisation of important high-grade resources. Furthermore, the importance of networking for TSL reinforces the fact that grassroots innovations are more likely to occur where there is a fertile environment, a basin of activists ready to 'do', experiment, and try new things. In 'geographical' terms, place identity and history matter. It seems that there is likely a trade-off between being in a favourable environment (a place already full of activists) and competition with other movements. 
The interconnections between social movements and grassroots innovations in terms of place open up several questions for future research. A more in-depth study of these interconnections might explore the transfer of practices or values in social movement spaces. Besides competition, it is possible that the innovations are enhanced and advanced, perhaps because they are transferred to other movements. Future studies might explore the spaces (geographical, social, and symbolic) of collaboration and competition and whether there is a segmentation (geographical, or of expertise) between movements. Although actors within social movements may divide themselves into smaller organizations based on nuances in opinion, there may be spaces to find common ground, especially within perspectives on whether change should come about through the current system or through advocating for systemic change.

\section{References}

Aiken, G., 2012. Community transitions to low carbon futures in the Transition Towns Network (TTN). Geography Compass 6 (2), 89-99.

Alloun, E., Alexander, S., 2014. The transition movement: questions of diversity, power and affluence. Simplicity Institute Report 14g, 1-24.

Amin, A., 2004. Regions unbound: towards a new politics of place. Geografiska Annaler 86 (1), 33-44.

Andrews, K. T., Biggs, M., 2006. The dynamics of protest diffusion: movement organizations, social networks, and news media in the 1960 sit-ins. American Sociological Review 71 (5), 752-777.

Bailey, I., Hopkins, R., Wilson, G., 2010. Some things old some things new: the spatial representations and politics of change of the peak oil relocalisation movement. Geoforum 41 (4), 595-605.

Barnes, N., 2004. AIDS organizations in Mexico City and Tijuana: comparing the effects of transnational networks on local community-based organizations. Working Paper, California Cultures Graduate Summer Research Fellow, Department of Sociology, University of California, San Diego, CA.

Beaumont, J., Nicholls, W., 2007. Between relationality and territoriality: investigating the geographies of justice movements in The Netherlands and the United States. Environment and Planning 39 (11), 2554-2574. 
Biddau, F., Armentia, A., Cottone, P., 2016. Socio-psychological aspects of grassroots participation in the Transition Movement: an Italian case study. Journal of Social and Political Psychology 4 (1), 142-165.

Boschma, R., 2005. Proximity and innovation: a critical assessment. Regional Studies 39 (1), 61-74.

Böhm, S., Bharucha, Z. P., Pretty, J., (2015). Ecocultures: Blueprints for Sustainable Communities. Routledge, New York.

Brangwyn, B., Hopkins, R., 2008. Transition Initiatives Primer. Version 26, Transition Network, Totnes, Devon.

Brown, A., 2014. The 2015 Legislature Will Be Utah's $2^{\text {nd }}$ Most Republican Since the Depression. http://utahdatapoints.com/2014/11/update-the-2015-legislature-will-beutahs-2nd-most-republican-since-the-depression

Brown, G., Krafti, P., Pickerill, J., \& Upton, C., 2012. Holding the future together: towards a theorisation of the spaces and times of transition. Environment and Planning A 44 (7), $1607-1623$.

Canham, M., 2014. Mormon Populace Picks Up the Pace in Utah. http://www.sltrib.com/news/1842825-155/mormon-populace-picks-up-the-pace

Caprotti, F., Bailey, I., 2014. Making sense of the green economy. Geografiska Annaler: Series B Human Geography 96 (3), 195-200.

Carlsson, C., 2008. Nowtopia: How Pirate Programmers, Outlaw Bicyclists, and Vacant-Lot Gardeners are Inventing the Future Today! AK Press, Chico.

Carlsson, C., Manning, F., 2010. Nowtopia: strategic exodus? Antipode 42 (4), 924-953.

Della Porta, D., Diani, M., 2006. Social Movements: An Introduction. Blackwell Publishers, Oxford.

Diani, M., 2000. Social movement networks virtual and real. Information, Communication \& Society 3 (3), 386-401.

Diani, M., 2003. Leaders or brokers? Position and influence in social movement networks. In: McAdam, D., Diani, M. (Eds.) Social Movements and Networks: Relational Approaches to Collective Action. Oxford University Press, Oxford, pp. 105-122.

Hiskanen, E., Nissila, H., Lovio, R., (2015). Demonstration buildings as protected spaces for clean energy solutions the case of solar building integration in Finland. Journal of Cleaner Production 109, 347-356.

Featherstone, D., 2003. Spatialities of transnational resistance to globalization: the maps of grievance of the Inter-Continental Caravant. Transaction of the Institute of British Geographers 28 (4), 404-421. 
Featherstone, D., 2005. Towards the relational construction of militant particularisms: or why the geographies of past struggles matter for resistance to neoliberal globalisation. Antipode 37 (2), 250-271.

Featherstone, D., 2008. Resistance, Space and Political Identities: The Making of CounterGlobal Networks. Wiley-Blackwell, Oxford.

Feola, G., 2014. Narratives of grassroots innovations: a comparison of voluntary simplicity and the transition movement in Italy. International Journal of Innovation and Sustainable Development 8 (3), p.250.

Feola, G., \& Him, M. R., 2016. The diffusion of the Transition Network in four European countries. Environment and Planning A. doi: 10.1177/0308518X16630989

Feola, G., Nunes, R., 2014. Success and failure of grassroots innovations for addressing climate change: The case of the Transition Movement. Global Environmental Change $24,232-250$.

Feola, G., Butt, A., 2015. The diffusion of grassroots innovations for sustainability in Italy and Great Britain: an exploratory spatial data analysis. The Geographical Journal. doi: $10.1111 /$ geoj.12153

Hammersley, M., Atkinson, P., 1995. Ethnography: Practices and Principles. Routledge, New York.

Hargreaves, T., Longhurst, N., Seyfang, G., 2013. Up, down, round and round: connecting regimes and practices in innovation for sustainability. Environment and Planning A 45 (2), 402-420.

Haxeltine, A., Seyfang, G., 2009. Transitions for the people: theory and practice of 'transition' and 'resilience' in the UK's Transition Movement. Working Paper 134, Tyndall Centre for Climate Change Research.

Hedström, P., 1994. Contagious collectivities: on the spatial diffusion of Swedish trade unions, 1890-1940. American Journal of Sociology 99 (5), 1157-1179.

Hoffman, S.M., \& High-Pippert, A., 2010. From private lives to collective action: recruitment and participation incentives for a community energy program. Energy Policy 38 (12), 7567-7574.

Hopkins, R., 2008. The Transition Handbook. Chelsea Green Press, White River Junction.

Hopkins, R., 2011. The Transition Companion: Making Your Community More Resilient in Uncertain Times. Green Books, Cambridge.

Hopkins, R., 2013. The Power of Just Doing Stuff: How Local Action Can Change the World. Green Books, Cambridge.

Kenis, A., Mathijis, E., 2014. (De)politicising the local: the case of the Transition Towns 
movement in Flanders (Belgium). Journal of Rural Studies 34, 172-183.

Kirwan, J., Ilbery, B., Maye, D., Carey, J., 2013. Grassroots social innovations and food localisation: an investigation of the local food programme in England. Global Environmental Change 23 (5), 830-837.

Leff, E., 2010. Degrowth, or deconstruction of the economy: towards a sustainable world. Critical Currents 6, 101-107.

Lim, M., 2014. Seeing spatially: people, networks and movements in digital and urban spaces. International Development and Planning Review 36 (1), 51-72.

Longhurst, N., 2015. Towards an "alternative" geography of innovation: alternative milieu, socio-cognitive protection and sustainability experimentation. Environmental Innovation and Societal Transitions 17, 183-198.

Massey, D., 2004. Geographies of responsibility. Geografiska Annaler 86 (1), 5-18.

May, D., (1987). Utah: A People’s History. University of Utah Press, Salt Lake City.

Middlemiss, L., Parrish, B. D., 2010. Building capacity for low-carbon communities: the role of grassroots initiatives. Energy Policy 38 (12), 7559-7566.

Miller, B., 2000. Geography of Social Movements: Comparing Antinuclear Activism in the Boston Area. University of Minnesota Press, Minneapolis.

Mulgan, G., 2006. The process of social innovation. Innovations: Technology, Governance, Globalization 1 (2), 145-162.

Mulugetta, Y., Jackson, T., Van der Horst, D., 2010. Carbon reduction at community scale. Energy Policy 38, 7541-7545.

Muraca, B., 2015. Concrete Utopia as education of desire: the role of social experiments in the transformation of the Social Imaginary. Paper presented at $11^{\text {th }}$ International Conference of the European Society for Ecological Economics, University of Leeds.

Neal, S., 2013. Transition culture: politics, localities and ruralities. Journal of Rural Studies $32,60-69$.

North, P., 2010. Eco-localisation as a progressive response to peak oil and climate change: a sympathetic critique. Geoforum 41 (4), 585-594.

North, P. Longhurst, N., 2013. Grassroots localization? The scalar potential of and limits of the 'Transition' approach to climate change and resource constraint. Urban Studies 50 (7), 1423-1438.

Norris, P., 2001. Digital Divide: Civic Engagement, Information Poverty, and the Internet Worldwide. Cambridge University Press, Cambridge.

Nicholls, W., 2007. The geographies of social movements. Geography Compass 1 (3), 607- 
622.

Ornetzelder, M., Rohracher, H., 2013. Of solar collectors, wind power, and car sharing: comparing and understanding successful cases of grassroots innovations. Global Environmental Change 23 (5), 856-867.

Pile, S., Keith, M., 1997. Geographies of Resistance. Routledge, London.

Pickerill, J., 2015. Cold comfort? Reconceiving the practices of bathing in British self-build eco-homes. Annals of the Association of American Geographers 105 (5), 1061-1077.

Pickerill, J., Maxey, L., 2009. Geographies of sustainability: low impact developments and radical spaces of innovation. Geography Compass 3 (4), 1515-1539.

Quilley, B. 2012. 'Resilience through relocalization: ecocultures of transition? Transition to a post-carbon, post-consumer society: new, traditional and alternative ways of living in the 'adjacent possible'. Working Paper, 2012-1, University of Essex, UK.

Routledge, P., 2003. Convergence space: process geographies of grassroots globalisation networks. Transactions of the Institute of British Geographers 28 (3), 333-349.

Schulz, C. Bailey, I., 2014. The spatial dimensions of the green economy and post-growth regimes: opportunities and challenges for economic geography. Geografiska Annaler B 96, 277-91

Seyfang, G., Longhurst, N., 2013. Desperately seeking niches: grassroots innovations and niche development in the community currency field. Global Environmental Change 23 (5), 881-891.

Seyfang, G., Smith, A., 2007. Grassroots innovations for sustainable development: towards a new research and policy agenda. Environmental Politics 16 (4), 584-603.

Seyfang, G., Haxeltine, A., Hargreaves, T., Longhurst, N., 2010. Energy and communities in transition: towards a new research agenda on agency and civil society in sustainability transitions. Working Paper No. EDM 10-13, The Center for Social and Economic Research on the Global Environment.

Seyfang, G., Longhurst, N., 2016. What influences the diffusion of grassroots innovations for sustainability? Investigating community currency niches. Technology Analysis \& Strategic Management 28 (1), 1-23.

Shawki, N., 2013. Understanding the transnational diffusion of social movements: an analysis of the U.S. solidarity economy network and transition US. Humanity \& Society 37 (2), 131-58.

First Unitarian Church, n.d. About Our Church. http://slcuu.org/about

Smith, A., 2011. The transition town network: a review of current evolutions and renaissance. Social Movement Studies 10 (1), 99-105. 
Smith, B., 2013. What makes SLC so white? http://cityweekly.net/TheDailyFeed/archives/2013/09/06/what-makes-salt-lake-city-sowhite

Smith, A., Seyfang, G., 2013. Constructing grassroots innovations for sustainability. Global Environmental Change 23, 827-829.

Soule, S. A., 2004. Diffusion processes within and across movements. In: Snow, D. A., Soule, S. A., Kriesi, H. (Eds.) The Blackwell Companion to Social Movements. Blackwell, Malden, pp. 294-310.

Strang, D., Soule, S., 1998. Diffusion in organizations and social movements: from hybrid corn to poison pills. Annual Review of Sociology 24 (1998), 265-290.

Tarrow, S., 2005. The New Transnational Activism. Cambridge University Press, New York.

Tarrow, S., McAdam, D., 2005. Scale shift in transnational contention. In: Della Porta, D., Tarrow, S. (Eds.) Transnational Protest \& Global Activism. Rowman \& Littlefield, Boulder, pp. 1-20.

Transition Network, n. d. About Transition Network. https://transitionnetwork.org/about/

Transition Salt Lake, 2011-2014. Steering group meeting minutes. Salt Lake City, Utah.

Walker, G., 2011. The role for community in carbon governance. Wiley Interdisciplinary Reviews: Climate Change 2 (5), 777-782.

Wells, P., 2011. The transition initiative as a grass-roots environmental movement: history, present realities and future predictions. Interdisciplinary Environmental Review 12 (4), 372-386.

Wright, E. O., 2013. Transforming capitalism through real utopias. American Sociological Review 78 (1), 1-25.

Please note: This study was submitted to the University of Utah's Internal Review Board for approval, IRB_00072682, and received exemption for further review on 4/16/2014 under Exemption Category 2. 